PEMERANAN TOKOH SYLVIA DALAM NASKAH THE TYPISTS KARYA MURRAY SCHISGAL TERJEMAHAN YURI AKHMAD $S$

\author{
Skripsi \\ Untuk memenuhi salah satu syarat \\ mencapai derajat Sarjana S-1 \\ Program Studi S-1 Seni Teater Jurusan Teater
}

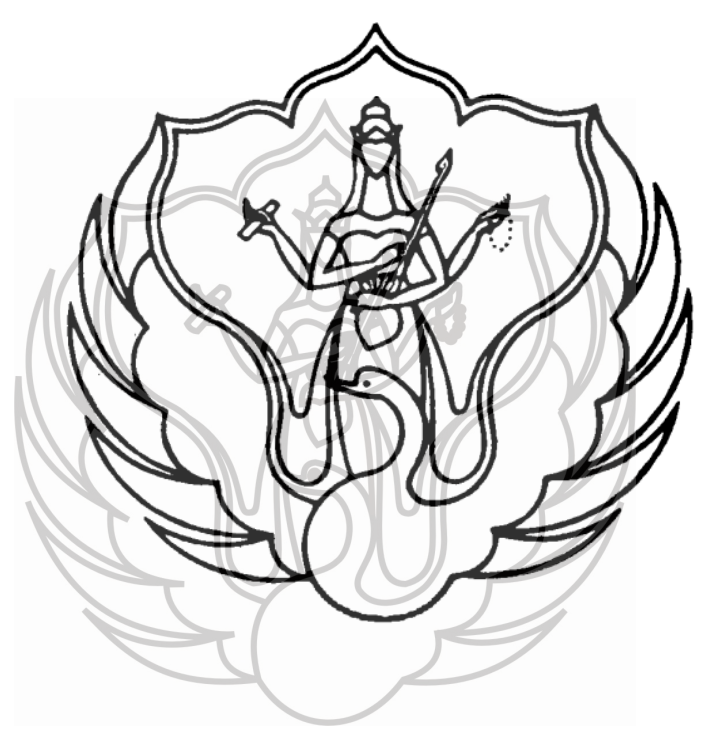

Oleh

Galuh Endang Subekti

NIM. 1310735014

FAKULTAS SENI PERTUNJUKKAN

INSTITUT SENI INDONESIA YOGYAKARTA

YOGYAKARTA

2017

UPT Perpustakaan ISI Yogyakarta 


\title{
PEMERANAN TOKOH SYLVIA DALAM NASKAH THE TYPISTS KARYA MURRAY SCHISGAL TERJEMAHAN YURI AKHMAD $S$
}

\author{
Skripsi \\ Untuk memenuhi salah satu syarat \\ mencapai derajat Sarjana S-1 \\ Program Studi S-1 Seni Teater Jurusan Teater
}

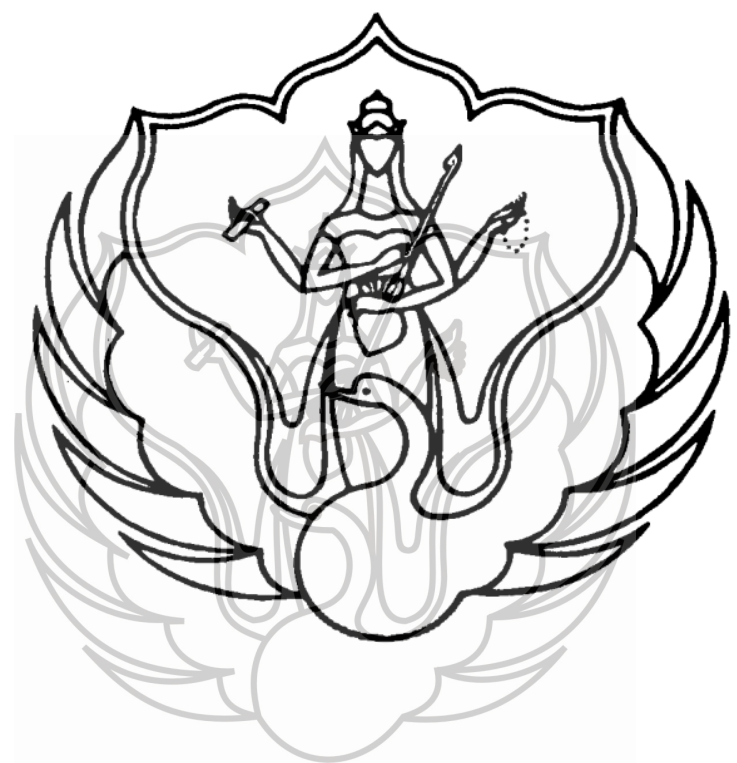

Oleh

Galuh Endang Subekti

NIM. 1310735014

FAKULTAS SENI PERTUNJUKKAN INSTITUT SENI INDONESIA YOGYAKARTA YOGYAKARTA

2017

UPT Perpustakaan ISI Yogyakarta 


\title{
PEMERANAN TOKOH SYLVIA DALAM NASKAH THE TYPISTS KARYA MURRAY SCHISGAL TERJEMAHAN YURI AKHMAD S
}

\author{
Oleh \\ Galuh Endang Subekti \\ NIM. 1310735014 \\ Telah diuji di depan Tim Penguji \\ Pada tanggal 14 juli 2017 \\ Dinyatakan telah memenuhi syarat \\ Susunan Tim Penguji
}

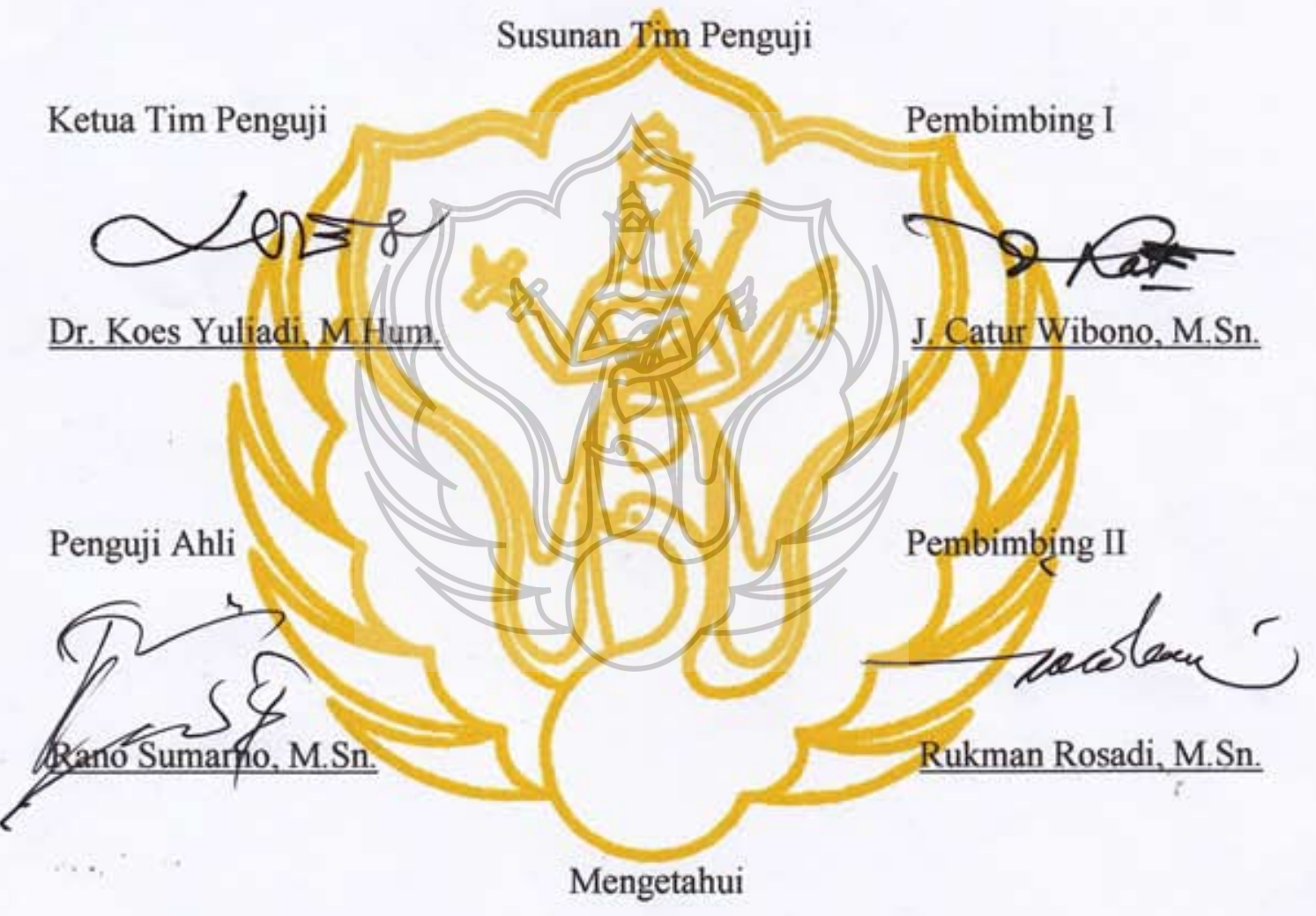

Yogyakarta, 2017

Dekan Fakultas Seni Pertunjukan

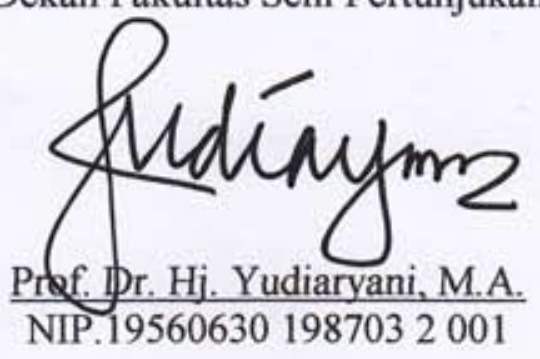




\section{SURAT PERNYATAAN}

Yang bertanda tangan di bawah ini :

Nama

Alamat

No. Telepon

Email
: Galuh Endang Subekti

: 23B karang rejo, metro timur, Lampung

: 085789333263

: galuhendang07@gmail.com

Menyatakan bahwa skripsi dengan judul:

Pemeranan Tokoh Sylvia Dalam Naskah The Typists Karya Murray Schisgal Terjemahan Yuri Akmad S. Benar-benar asli dan dikerjakan sendiri, tidak terdapat karya yang pernah diajukan untuk memperoleh gelar sarjana di Perguruan Tinggi, dan sepanjang pengetahuan saya dalam skripsi ini ditulis sendiri dan tidak terdapat karya atau pendapat yang pernah ditulis oleh orang lain, kecuali yang secara tertulis diakui dalam skripsi ini dan disebut pada daftar Kepustakaan.

Apabila pernyataan saya ini tidak benar, saya/sanggup dicabut hak dan gelar saya sebagai Sarjana Seni dari Program Studi Teater Jurusan Teater Fakultas Seni Pertunjukan Institut Seni Indonesia Yogyakarta.

Yogyakarta, 14 juli 2017

Galuh Endang Subekti

\section{UPT Perpustakaan ISI Yogyakarta}




\section{KATA PENGANTAR}

Puji syukur untuk Tuhan Yesus Yang Maha Agung, atas limpahan Berkat, Karunia, Lindungan dan Kasih SayangNYA yang tak terbendung sehingga skripsi dengan judul "Pemeranan Tokoh Sylvia Dalam Naskah The Typists Karya Murray Schisgal Terjemahan Yuri Ahmad S" dapat terselesaikan tepat delapan semester dalam menempuh pendidikan sarjana di Institut Seni Indonesia Yogyakarta. Skripsi disusun sebagai salah satu syarat menyelesaikan studi dan dalam rangka memperoleh gelar Sarjana Seni pada Program Studi Teater Fakultas Seni Pertunjukan Institut Seni Indonesia Yogyakarta.

Terimakasih dan dekapan hangat untuk kedua orang tua yang selalu mendukung segala kegiatan putri bungsunya secara moral maupun materil, maaf terkadang sedikit memaksa. Ucapan terimakasih rasanya tak cukup untuk membalas semua apa yang telah kalian berikan. Ibu Sugiati dan Bapak Mustafa semoga selalu dalam lindungan Tuhan, diberikan kesehatan, dihebatkan dalam hidup dan kebahagiaan selalu bersama kalian hingga akhir nanti.

Bapak Johanes Catur Wibono, S.Sn, M.Sn selaku pembimbing I yang tak lelah mengkoreksi tulisan hingga banyak catatan yang tertera setiap konsultasi. Bapak Rukman Rosadi, M.Sn. selaku pembimbing II, selalu memberi motivasi dan solusi saat mental sedang down dan raga lelah menjadi up and never give up. Terimakasih untuk kedua pembimbing yang dengan sabar dan telaten menghadapi segala keluh-kesah sehingga penulisan skripsi ini mendekati harapan. Ucapan terimakasih juga dihaturkan kepada :

\section{UPT Perpustakaan ISI Yogyakarta}


1. Rektor ISI Yogyakarta Dr. Agus Burhan, M. Hum beserta jajaran staf pegawai rektorat.

2. Dekan FSP ISI Yogyakarta Prof. Dr. Yudiaryani, MA. Beserta jajaran staf pegawai dekanat.

3. Dr. Koes Yuliadi, M.Hum. selaku Ketua Jurusan Teater, Ketua Tim Penguji dan Philipus, M.Sn Nugroho Hari Wibowo, Sekretaris Jurusan Teater.

4. Rano Sumarno, M.Sn. selaku Dosen Penguji Ahli.

5. Purwanto M.Sn. selaku Dosen Wali

6. Seluruh dosen dan staf Jurusan Teater ISI Yogyakarta. Terimakasih untuk ilmu dan pengalaman yang diberikan.

7. Himpunan Mahasiswa Jurusan Teater ISI Yogyakarta beserta seluruh anggota HMJ, terimakasih selama ini sudah membantu.

8. Lek-lek Jurusan Terater. Lek Sar, Lek Wandi dan Lek Margono. Lek Sar terimakasih untuk karak yang selalu Lek Sar hidangkan disetiap latihan.

9. Kedelapan saudaraku, ayu dan abangku terimakasih sudah mensupport. Doa selalu terucap untuk kalian semua.

10. Pace Diki dan teman-teman seni rupa yang sudah mencorat-coret tubuh Sylvia dengan cat. Kita berkarya bersama teman.

11. Kelas Pagi Yogya yang memberikan tempat untuk pentas.

12. Mas Broto Wijayanto, Pak Jemek, Reza Ende, Dodi, Mas Nanang terimakasih untuk teknik pantomime yang dibagi. Teman-teman DAC

\section{UPT Perpustakaan ISI Yogyakarta}


terimakasih atas pertemanan yang indah, sekarang kita dapat berkomunikasi dalam bahasa isyarat.

13. Pasa Deparaga selaku partner main. Terimakasih untuk tantangan yang diberikan, sehingga sekarang bisa menaklukkan pantomime

14. Flying Balloons Puppet shadow kalian keren, terimakasih telah memperindah pentas The Typist.

15. Adorrebel terimakasih untuk dukungan kalian, semoga rebelion kalian tidak menjadikan kalian insan seni yang ingkar pancasila dan dapat menjadi seniman sejati.

16. Ikhsan selaku pimpro.

17. Mailani yang membantu brain logistic.

18. Bang Babam dengan segala kepanikannya mencarikan wig dan design poster yang keren.

19. Teman-teman Teater Teras 2013.

20. Teater Tongkat 2014.

21. Teater Renjana 2016.

22. Teman-teman teater Pojok Purwokerto yang bersedia memberi Venue, mengapresiasi dan mengevaluasi pementasan pertama The Typist.

23. Teman-teman seperjuangan TA, Niyah, Birgita, Estri, Mas Gandung, Pasa, Mas Hakim, Mas Wachid dan Mas Kukuh.

24. Semua pihak yang mendukung Tugas Akhir ini yang tidak dapat disebutkan satu persatu.

\section{UPT Perpustakaan ISI Yogyakarta}


Karya ini masih jauh dari kesempurnaan, oleh karena itu karya ini menerima segala masukan dan kritik membangun untuk karya-karya berikutnya. Semoga karya ini dapat memberi manfaat.

Demikian, dengan segala hormat dan kerendahan hati serta kemampuan yang ada tuntas sudah Tugas Akhir dengan minat utama keaktoran sebagai salah satu syarat untuk menempuh Jenjang S1 Fakultas Seni Pertunjukan, Institut Seni Indonesia Yogyakarta.

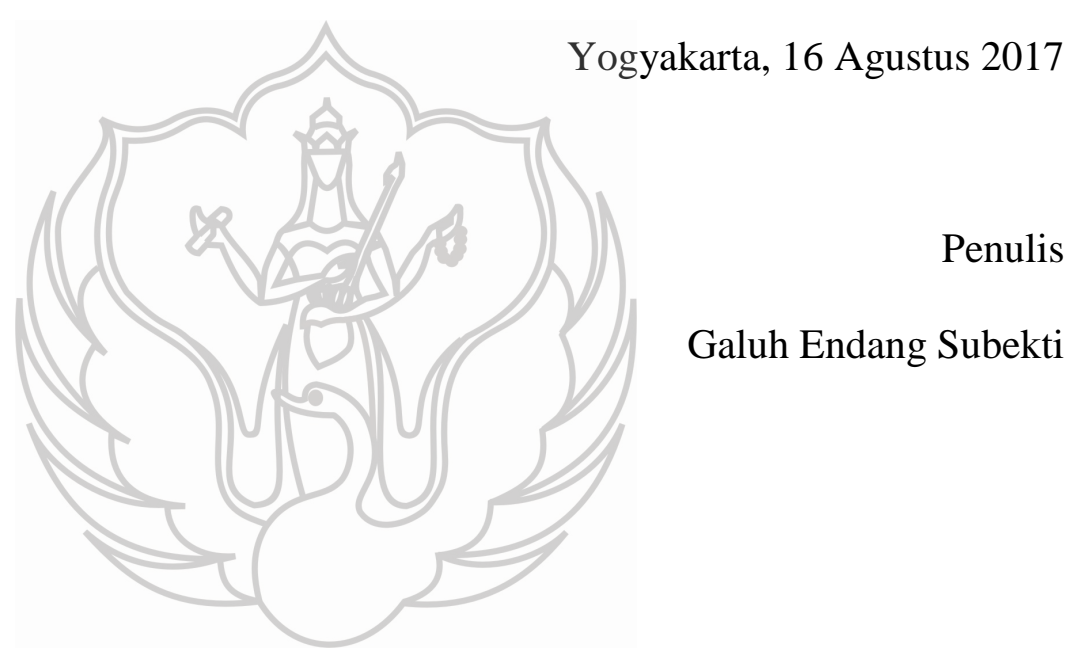

\section{UPT Perpustakaan ISI Yogyakarta}




\section{DAFTAR GAMBAR}

Gambar 1. Tokoh paul dan Sylvia film The Typists

Gambar 2. Pertunjukan The Typists Produksi Teater Kepribadian

Gambar 3. Pentas Doku Mime, sumber: Broto Wijayanto, 2017

Gambar 4. Pentas Doku Mime, sumber: Broto Wijayanto, 2017

Gambar 5. Olah vocal teknik bernyanyi, sumber: Dul , 2017

Gambar 6. Reading naskah The Typisst, Sumber: fauziah 2017

Gambar 7. Pengadeganan realis the typist, sumber: Fauziah, 2017

Gambar 8. Pentas Purwokerto, The Typist, sumber: Dul, 2017

Gambar 9. Live music sebelum pementasan the Typists, Sumber: DE Project, 2017

Gambar 10. Bazar handycraf sumber: DE Project 2017

Gambar 11. Menikmati hidangan diruang pertunjukan sumber: DEProject, 2017

Gambar 12. Proses Body panting pada kostum sumber :DE Project, 2017

Gambar 13. Perkenalan Tokoh Paul Dan Syyia sumber: De Project, 2017

Gambar 14. aktivitas kerja Sylvia, Sumber; DE Project 2017

Gambar 15. Sylvia memberi tau cara Mengetik, Sumber: DE Projec, 2017

Gambar 16. waktu istirahat dikantor, Sumber: DE Project, Kelas Pagi Yogyakarta,2017

Gambar 17. Sylvia kesal dengan Bos, Sumber: DE Project

Gambar 18 Pysical Theatre, menceritakan latar belakanng,Sumber:DE Project 2017.

Gambar 19. Kepedulian Paul saat memakaikan Jas, Sumber: DE Project, 2017

Gambar 20. Sylvia dan Paul memulai konflik Percintaan, sumber : DE Project

Gambar 21. Sylvia Merayu Paul Sumber: De Project, 2017

Gambar 22. Sylvia mengharap cinta Paul Sumber: DE Project, 2017 
Gambar 23. Kesalahpahaman Antara Paul dan Sylvia Sumber: DE Project, 2017

Gambar 24. Sylvia kesal dengan harapan palsu Paul Sumber:DE Project

Gambar 25. Sylvia menelfon keluarganya saat kesepian, Sumber: DE Project, 2017

Gambar 26. Paul,Sylvia saling menceritakan latar belakang Sumber: Deproject, 2017

Gambar 27. mabuk akan kehilangan pekerjaan, Sumber: Deproject,2017

Gambar 28. Sylvia berharap untuk dinikahi Sumber: DE Project, 2017

Gambar 29. Adegan percintaan dan harapan palsu paul Sumber: De Project, 2017

Gambar 30. Percintaan dan harapan palsu Sumber: De Project, 2017

Gambar 31. Sylvia mulai tidak ingin berharap dengan Paul Sumber: DE Project, 2017

Gambar 32. Sylvia saat 60 tahun kehidupan yang baik Sumber: DE Project, 2017

Gambar 33. Tokoh Sylvia dan paul selesai dengan permasalahan Hidupnya, sumber: DE Project 2017

Gambar 34. Design poster pementasan The Typists . Design: Babam

\section{UPT Perpustakaan ISI Yogyakarta}




\title{
PEMERANAN TOKOH SYLVIA DALAM NASKAH THE TYPISTS KARYA MURRAY SCHISGAL TERJEMAHAN YURI AKHMAD S
}

Oleh

Galuh Endang Subekti

\begin{abstract}
Abstrak
Manusia modern saat ini telah mengalami perubahan cara pandang dengan berbagai macam persoalan menyangkut individu bahkan kelompok. Penyebabnya begitu kompleks, dengan kemajuaan saat ini manusia modern lebih banyak mengikuti keinginan yang sebenarnya bukan pilihanya. Manusia mengangap bahwa dirinya baik-baik saja tanpa sadar bahwa dirinya telah menjadi objek dan mengalami ketidakberadaan. Manusia modern saat ini tanpa sadar telah mengalami dan merasakan kehampaan, harapan, kesepian, dan kecemasan. Sejak Sylvia muda hingga tua Sylvia banyak mengalami perubahan. Kesadaran sebagai manuisa yang kehilangan eksistensi didukung oleh hadirnya Paul. Pementasan akan disajkan dengan konsep pantomim dan gaya akting realis. Dengan begitu aktor dituntut untuk bisa mengabungkan konsep tersebut dengan capaian semaksimal mungkin.

Kata kunci : Teater, aktor, Sylvia, akting, teater tubuh, pantomim.
\end{abstract}

\begin{abstract}
Modern man has now undergone a change of perspective with various problems concerning individuals and even groups. The reason is so complex, with the current pace of modern man more follow the actual desire is not the choice. Humans assume that he is alright without realizing that he has become an object and experiencing non-existence. Today's modern man has unknowingly experienced and felt the void, hope, loneliness, and anxiety. Since Sylvia young to old Sylvia many changes. Awareness as a manuisa who lost existence is supported by the presence of Paul. Staging will be presented with the concept of pantomime and realist acting style. With so actors are required to be able to combine the concept with the achievement as much as possible.
\end{abstract}

Key word: Theatre, actor, Syvia, acting, physical theatre, pantomime. 


\section{BAB I}

\section{PENDAHULUAN}

\section{A. Latar Belakang}

Lakon The Typists karya Murray Schisgal adalah naskah yang menceritakan dua tokoh, Paul dan Sylvia yang bekerja di sebuah perusahaaan sebagai juru ketik. Keberadaan dan keadaannya sekarang ini sebenarnya bukanlah pilihan mereka. Apa yang mereka inginkan adalah bebas tanpa harus memikirkan keluarga dan pekerjaannya saat ini. Pada lakon ini Paul dan Sylvia semakin menua dari usia 25 s/d 60 tahun. Pada akhirnya mereka menerima dan menikmati kehidupannya saat usia 60-an.

Sylvia dalam lakon The Typists tidak lagi memiliki kekuasaan diri. Ini contoh dari manusia modern yang cenderung menanyakan "apa yang sebenarnya diinginkan dalam hidup?". Tokoh Sylvia tidak pernah mengalami kekurangan keuangan dalam menjalani hidup. Tapi Sylvia masih saja merasa tidak memiliki apapun karena kekurangan satu hal "CINTA". Pada akhirnya Sylvia mengalami kekosongan, kesepian, dan kecemasan.

Dalam menjalani hidupnya ia terjebak dalam ketidakberadaan terhadap dunia. Dunia sudah tidak tampak di mata Sylvia, tapi kodrat manusia sebagai subjek tidak bisa dihindari, sehingga Sylvia menjalani hidup dalam bayangan. Sylvia tidak memandang dunia sebagai fakta melainkan harapan di balik fakta. Sylvia akhirnya menemukan lagi perasaan- perasaannya, dirinya mulai sadar

\section{UPT Perpustakaan ISI Yogyakarta}


karena Sylvia tahu apa yang diinginkannya. Kesadaran inilah yang membuat kepribadian Sylvia tumbuh menjadi berada di dunia.

Naskah ini adalah kritik terhadap manusia modern saat ini. Kebanyakan manusia modern tidak tahu apa yang sebenarnya mereka inginkan. Hanya sekedar mengikuti perkembangan dan tidak tahu tujuan dari pilihannya. Refleksi dari naskah ini penting untuk penonton supaya tahu apa yang saat ini mereka alami sebagai manusia modern.

Melihat fenomena yang ada saat ini seni peran harus sangatlah bermanfaat untuk menyampaikan pesan kepada masyarakat. Pengaruh perkembangan zaman manusia mengalami perubahan cara pandang terhadap berbagai macam persoalan yang menyangkut individu atau kelompok. Hal ini yang mungkin menjadi faktor manusia kehilangan akan eksistensinya. Pertunjukan ini penting untuk masyarakat modern saat ini agar mereka mampu dan bersikap Sadar diri, Masyarakat modern dapat sadar ruang dan waktu atau menempatkan dirinya dalam setiap aktivitas keseharian dimanapun mereka berada sehingga dapat menentukan keputusan yang tepat untuk mengatasi masalah dan pilihan hidup yang semakin kompleks.

Terbuka terhadap pengalaman-pengalaman, Sekarang sudah masuk dalam erasiber space atau dunia tanpa sekat jadi Masyarakat dapat dengan bebas mengakses semua informasi dari berbagai belahan dunia. Banyak peristiwa diluar pengalaman keseharian yang begitu luar biasa untuk dijelajahi. Terbuka terhadap pengalaman-pengalaman baru mampu membuka wawasan seseorang dan senantiasa siap menerima perubahan setelah menilai adanya beberapa kekurangan dan kelebihan yang dihadapi.

\section{UPT Perpustakaan ISI Yogyakarta}


Memiliki kepekaan terhadap perencanaan masalah yang dihadapi masyarakat modern adalah mengenai eksistensi manusia itu sendiri hingga menimbulkan rasa hampa menjalani kehidupan. Perencanaan yang matang mengenai target kedepan sangat dibutuhkan. Menerapkan target hidup yang harus dicapai dapat meningkatkan gairah hidup dan menjadikan pribadi yang efisien. Sehingga dengan berjalannya waktu manusia akan menemukan eksistensinya serta tidak mudah menyerah kepada nasib perencaan yang tertata serta menyediakan plan $B$ jika rencana awal gagal membuat kita punya banyak pilihan untuk tindakan selanjutnya.

Sikap-sikap seperti itulah yang harus menjadi kesadaran supaya menjadi manusia yang berguna dalam perkembangan zaman saat ini. Seorang pemeran yang baik adalah pengamat yang baik, aktor harus mampu menjiwai setiap tokoh yang akan dimainkan. Seorang aktor juga perlu mempunyai daya tarik, cerdas, kreatif dan mampu membuat penonton tidak monoton terhadap aktor. Setiap penciptaan karya seni kebaruan dan keunikan sangat diperlukan.

Dalam lakon The Typists teknik Pantomim akan dijadikan pilihan dalam pertunjukan ini. Jika wajah ekpresi tidak membawa kedunia berbeda itu hanya akan bersifat impasif dan mumi. Menjadi seperti topeng dan itu membawa kita ke korporeal mime" hanya audio, tubuh dan ekspresi juga penting untuk mendukung pesan dari teks tersebut.

\footnotetext{
${ }^{1}$ Decroux Etinne, The Decroux (New york, 2008), hlm. 45
}

\section{UPT Perpustakaan ISI Yogyakarta}


Tapi bisakah kita mencampur mime dan kata-kata? Ya, ketika keduanya miskin, karena saat itu seorang melengkapi yang lain”². Hal ini menjelaskan bagaimana teks dan mime menjadi satu dan saling melengkapi. Dengan membaca buku Decroux maka aktor semakin kuat dengan pilihanya untuk menyatukan teks dengan pantomim. Tentu banyak kesulitan di dalam pencarian bentuk dan ekspresi yang bertumpuk. Ada hal yang memungkinkan untuk dapat menyatukanya, seperti Decroux seniman pantomim di dalam bukunya Words on Mime. Buku ini berisi pengertian pantomim dan membahas angapan-angapanya tentang karya sastra dan pantomim. Menurut dexcroux kata-kata adalah metode ekspresi yang paling alami. Seni perasaan dan ekspresi harus dimulai dengan teksteks kehidupan yang digerakan oleh kata cenderung meluap kedalam tubuh. Jika kehidupan meluap ke dalam tubuh dan cepat berakhir itu karna tidak kemampuan aktor. "3" "Kekayaan logika adalah salah satu hal yang utama dalam pantomime yang mampu menciptakan imajinasi dengan logika benda dan ruang"4. Karya ini menjadi tantangan bagi seorang aktor untuk bisa mempresentasikanya dalam sebuah pertunjukan Teater.

Dalam pementasan ini aktor akan memerankan tokoh Sylvia. Dengan loncatan usia yang sangat signifikan dan perubahan bentuk tubuh. Tentu menjadi tantangan bagi seorang aktor untuk bisa memerankan tokoh ini dengan teknik pantomim. Hal inilah yang kemudian dipertimbangkan untuk menjadikan alasan yang kuat tokoh ini dijadikan pilihan sebagai karya tugas akhir keaktoran.

\footnotetext{
${ }^{2}$ Decroux Etinne, Words on Mime (California, 1985), hlm. 32.

${ }^{3}$ Decroux Etinne.op.cit.hlm..47

${ }^{4}$ Wawancara dengan guru pantomim. Ende Reza. Yogyakarta: 12 maret 2017. Jam 17:00
} 


\section{B. Rumusan Penciptaan}

Teater merupakan seni kerja kolektif ide dari tim kreatif tentu saja diperlukan dalam pertunjukan ini. Berdasarkan latar belakang yang telah diuraikan di atas, tentu saja banyak persoalan yang harus dipecahkan dari konsep pantomim hinga disatukanya dengan teks. Adapun rumusan penciptaan kali ini yaitu: Bagaimana memerankan tokoh Sylvia dengan teknik pantomim dalam lakon The Typists?

\section{Tujuan Penciptaan}

Melalui ide dan gagasan yang telah diuraikan pada rumusan penciptaan tentu saja ada tujuan sebagai seorang pengkarya yakni: Mampu memerankan tokoh Sylvia dengan teknik pantomim dalam lakon The Typists.

\section{Tinjauan Karya}

\section{Penciptaan Terdahul}

Dari sejumlah informasi dan sumber, ada begitu banyak pementasan lakon The Typists. Lalu ini yang akan dijadikan pembanding untuk karya selanjutnya adalah sebagai berikut:

a. Pementasan The Typists disutradarai oleh Glen A. Jordan dan diproduksi oleh Lewis Freedman, di Hollywood Theater Televisi, Los Angeles, dengan aktor Anne Jackson dan Eli Wallach.

\section{UPT Perpustakaan ISI Yogyakarta}




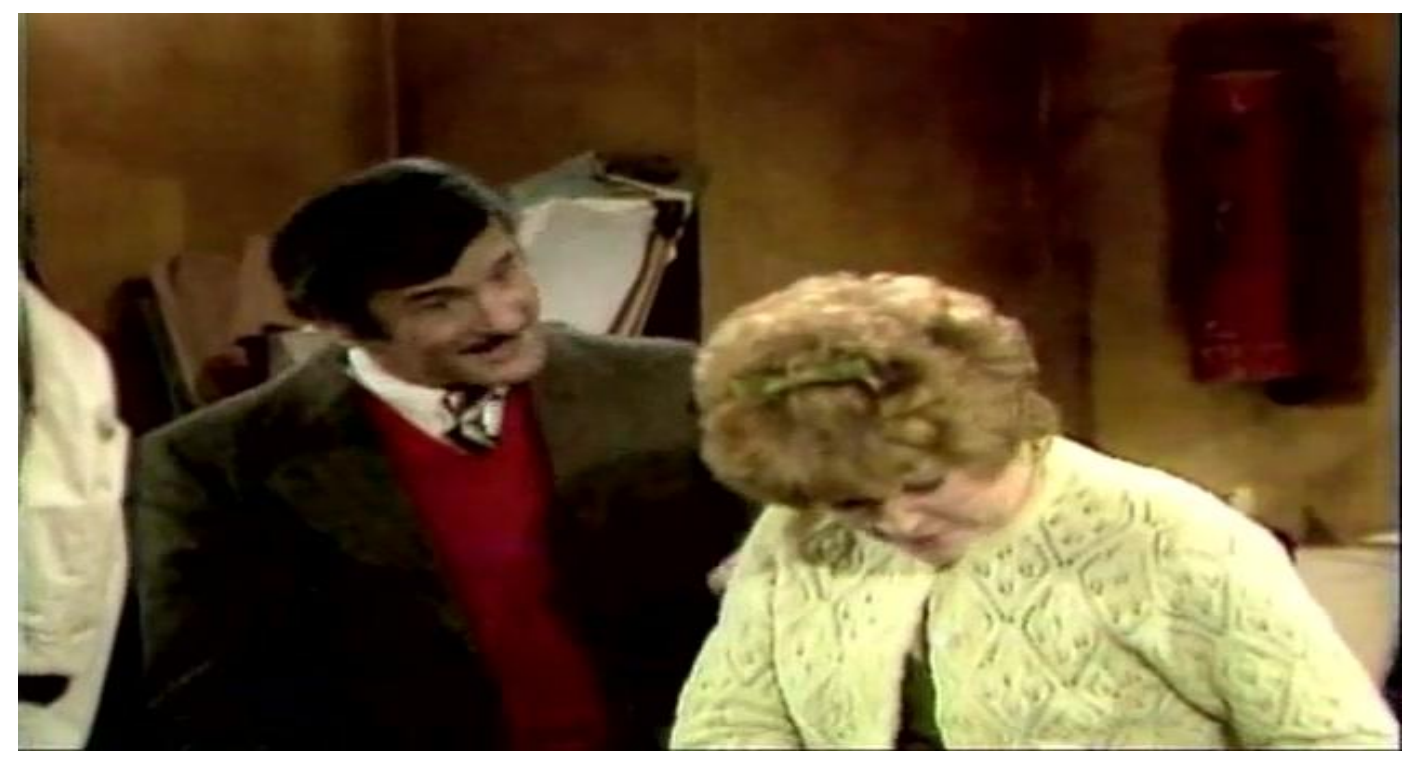

Gambar 1.

Tokoh Paul dan Sylvia Film The Typists Broadway Theatre. (Sumber: Film The Typists produksi Broadway Theatre tahun 1997, capture pada menit 09:30)

Setelah melihat pertunjukan yang disutradarai oleh Glen A. Jordan dengan para aktor ini banyak sekali kelebihan dan kekurangannya. Ini akan dijadikan pembanding untuk pertunjukan selanjutnya. Pada pertunjukan yang disajikan oleh Broadway Theatre aktor tua ini tentu saja pada tahap yang mudah dapat dibantu dengan umur yang sama. Tak ada perubahan kostum dan fisik pada pertunjukan ini. Pertunjukan ini bisa disebut realis, terlihat dari seting pangung dan realitas yang ada di dalam kantor. Pada penciptaan tokoh ini tentu saja berbeda, aktor harus bisa merubah umur aslinya dari 23 tahun sampai 60 tahun. Tentu banyak perubahan dari segi psikologi (pola pikir tokoh), fisiologi (perubahan-perubahan yang nampak pada fisik ), sosiologi (interaksi tokoh dengan lingkungan ia tinggal) karna perubahan waktu yang sangat jauh.

\section{UPT Perpustakaan ISI Yogyakarta}


b. Dipublikasikan Tanggal 9 oktober 2016 disutradarai oleh Teater Kepribadian, NSD pascasarjana (1987) New Delhi, dengan aktor Bharti Sharma dan Mohit Tripathi.

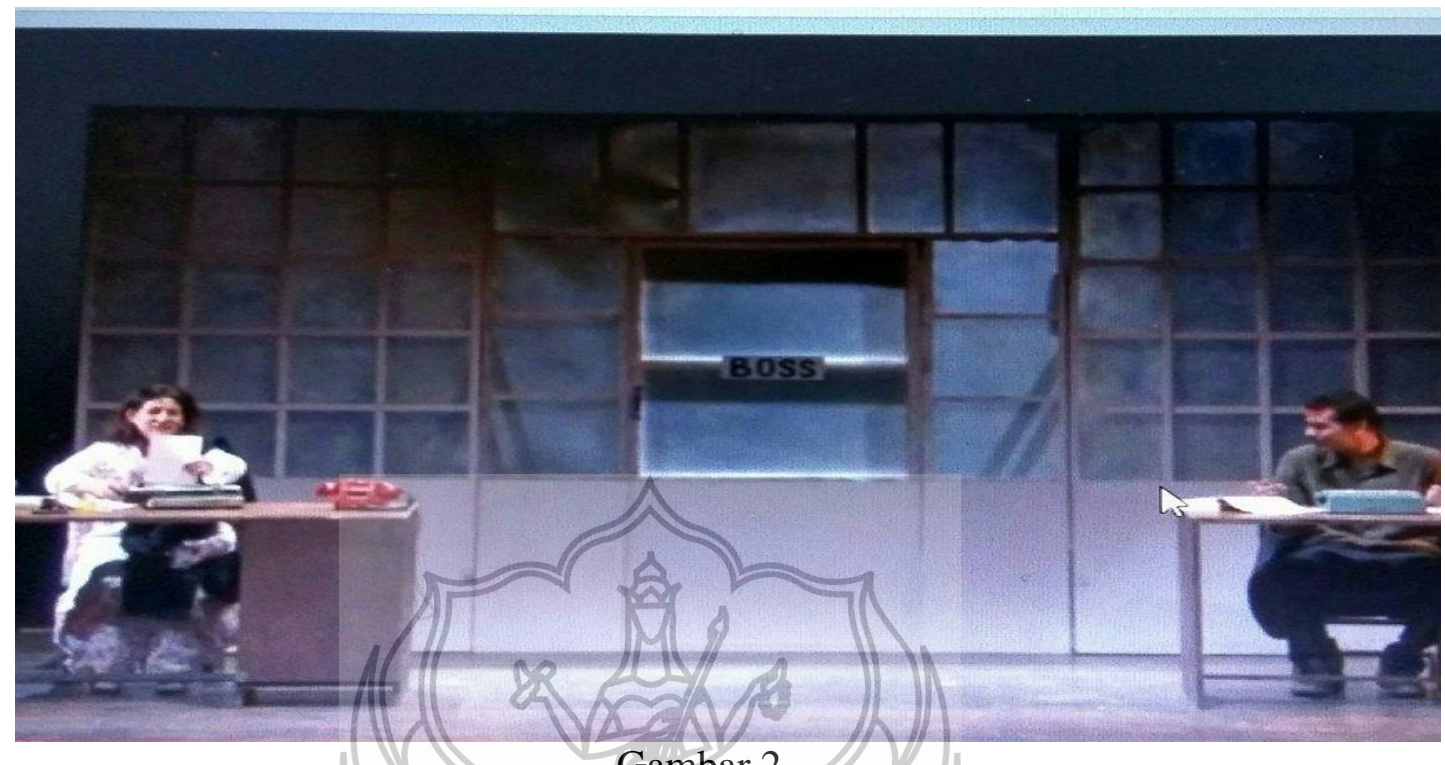

\section{Gambar 2}

Pertunjukan The Typists tokoh Paul Dan Sylvia(Sumber: Pertunjukan teater diproduksi Teater Kepribadian.2014 Capture pada menit 11:30)

Dari peristiwa pertunjukan yang terdahulu disajikan secara realis mengetik dilakukan dengan mesin ketik, setting divisualisasikan seperti sesungguhnya, suasana musik yang menyatu dengan adegan. Naskah ini disadur ke latar dan tempat kejadian di India.

Dalam penciptaan kali ini aktor akan mengandalkan tubuhnya. Dengan teori Peter Brook "The Shifting Point” aktor akan mencari berbagai kemungkinan bentuk tubuh dengan tekhnik pantomim untuk dapat menghantarkan imajinasi penonton pada peristiwa yang diciptakan di atas panggung. Memindahkan sepenggal aktivitas keseharian penonton ke atas panggung.

\section{UPT Perpustakaan ISI Yogyakarta}




\section{E. Landasan Teori}

Konsep pertunjukan dalam naskah The Typists ini akan menggunakan teori Peter Brook. Selama perjalanannya Peter Brook banyak melakukan eksperimen terhadap aktor dan dirinya. "Sesuatu yang menjadi basis dari pengalaman teater apa yang kami sebut sebagai “make believe"secara sederhana adalah peralihan dari yang tampak ke yang tidak tampak dan sebaliknya"s.

Peter Brook banyak melakukan perjalanan untuk menemukan teater adalah bagian dari kehidupan sehari-hari dan penting atau tidaknya untuk masyarakat. Peter Brook juga mengungkapkan pentingnya teater untuk bisa berjumpa dengan orang. "The Shifting Point" Peter Brook mengatakan bahwa pengalaman berteater sebenarnya adalah menghubungkan dua bentuk kenyataan yaitu dunia imajiner dan dunia keseharian penonton. ${ }^{6}$

Konsep ini melahirkan teori "dua dunia" yang/dipahami bahwa aktivitas pemain secara fisik yang aktif dan konvensi penonton yang pasif bertemu dalam sebuah permainan, dan permainan ini mampu memberi pengalaman khusus bagi keduanya. Permainan ini oleh Peter Brook disebut sebagai "The Shifting Point".

"Harapan kita satu-satunya ternyata berada dalam perbedaan besarmempertemukan yang saling bertentangan- sehinga benturan antar konvensi yang muncul rasa senang dari perasaan ngeri dan rasa sakit akan diikuti gelak tawa usaha penjelajah waktu dan kesadaran, penjelajah ritual, cinta, dan kematian, akan diikuti dengan kerikil besar kehidupan dan hidup. Teater adalah perut di mana metamorfosa makanan menjadi dua macam kualitas: kotoran badan dan mimpi-mimpi.",

${ }^{5}$ Peter Brook, Shifting Poin. (Yogyakarta, 2002), hlm.8

${ }^{6}$ Shomit Mitter, Stanilavsky. Brech, Grotowski, Brook: Sistem Pelatihan Lakon terjemahan Yudiaryani (Yogyakarta, 2002), hlm. 33

${ }^{7}$ Peter Brook,op.cit.hlm.34

\section{UPT Perpustakaan ISI Yogyakarta}


Pentingnya teater di dalam masyarakat juga bisa menyampaikan pesan baik dan buruk. Dari perbedaan itu kita bisa melihat dari seluruh pengalaman dari beberapa manusia yang ada di sekitar kita. Sylvia mengalami perbedaan dalam keluarganya yang selama ini ia bisa bertahan dengan tidak bebas. Sehingga ia menjelajah dalam percintaan itulah kerikil selama kehidupannya.

"Jika kita menerima kesan meyakinkan (convincing impression) bahwa suatu momen hidup telah terpenuhi secara lengkap (utuh) di atas pentas. Hal itu dimungkinkan karena berbagai kekuatan muncul atau berasal dari penonton atau aktor mempertemukanya pada suatu titik tertentu pada waktu yang bersamaan." 8

Pengalaman seorang aktor juga sangat diperlukan dalam dunia teater.

Penghayatan setiap perjalanan yang dilakukan tentu sangat bermanfaat untuk sebuah pertunjukan. Banyak kemungkinan-kemungkinan ingatan atau perasaan itu muncul untuk membangun suasana setiap adegan.

"Tugas aktor tentu saja sangat kompleks ketimbang dengan seorang warta berita itu. Jalan akan terbuka bila ia melihat bahwa suatu kehadiran atau pergelaran itu tidak berjarak. Jarak adalah suatu komitmen dalam arti total: kehadirannya adalah suatu komitmen total pada the living moment. Keduanya berjalan sama. Karena alasan ini diadakan pemilihan yang ketat terhadap pengunaan latihan-latihan untuk mengembangkan irama, pendengaran, tempo, pitch ensamble thinking, atau kehati-hatian yang kritis yang sesuai dengan apa yang dituntut oleh drama itu. Kalau sang aktor benar-benar merasakan bahwa pertanyan itu ialah pertanyaan miliknya sendiri maka tak dapat disangkal, ia akan mampu menangkap sesuatu kebutuhan untuk mengambil bagian di dalamnya. Dari kebutuhan akan suatu mata rantai dengan penonton akan muncul kejelasan (clarity) yang mutlak.",9

"The Shifting Point" (perpindahan titik tekan), sebuah permainan yang menghasilkan pengertian adanya ragam kebenaran. Kebenaran selalu bergerak, satu kebenaran akan mengungkap adanya kebenaran yang lain.

${ }^{8}$ Ibid. hlm. 22

${ }^{9}$ Ibid. hlm. 15

\section{UPT Perpustakaan ISI Yogyakarta}


Kebenaran yang beragam menyebabkan seseorang mampu melihat berbagai perspektif dalam sudut pandangnya." $"$

“The Shifting Point” juga bergerak melampaui batas antara dunia pemain dan penonton. Dalam pertunjukan The Typists akan dicoba untuk mempertemukan berbagai kutub yang mungkin bertentangan. Mempertemukan dunia keseharian dengan dunia imajiner. Mempertemukan kebaikan dan keburukan dari berbagai perspektif sudut pandang. Mempertemukan pencipta/seniman dengan penonton atau penikmatnya.

Teori yang dipakai untuk menganalisis tokoh dari Pskikologi fenomenologi eksistensialisme berfungsi untuk mengkomunikasikan konsep, gagasan umum, pola, atau bentuk kreatif penciptanya kepada penonton atau penikmat.

Paul dan Sylvia adalah tokoh eksistensialisme yang menginginkan kebebasan dalam tanggung jawab dari pekerjaan dan hidupnya bersama keluarganya. "Manusia adalah bebas, atau lebih tepatnya, manusia adalah kebebasan. Dengan kebebasan itu manusia menciptakan esensinya mendahului esensi adalah bebas"11.

Sylvia yang sebenarnya adalah tokoh eksistensi ingin sebenarnya hidupnya bebas. Seperti halnya ia selalu bermimpi untuk bisa pergi ke suatu tempat dan tak ada satu orang pun. Kepalsuan yang sebenarnya adalah ia bertahan bekerja sampai tua, yang ia inginkan sebenarnya adalah mendapatkan cinta dari Paul dan Bos namun harapan itu sia-sia.“ Pikiran, gerak-gerik manusia, cinta, rasa keadilan, dan

\footnotetext{
${ }^{10}$ Shomit Mitter. op. cit. hlm.202

${ }^{11}$ Muzairi, Eksistensialisme Jean Paul Sartre (Yogyakarta, 2002), hlm. 5
} 
seluruh ungkapan manusia semuanya dipecahkan dalam proses-proses benda atau materi. Dan manusia menjadi suatu hal yang tak lebih dari pada sekedar mesin"12. Untuk dapat mendukung dan menganalilsis tokoh tersebut maka akan digunakan teori Psikologi Eksistensi dan Fenomenologi:

"Heidegger menggunakan fenomenologi metode untuk menganalisis gejala-gejala psikologis. Berdasarkan fakta-fakta. Jadi psikologi eksistensialisme dapat dirumuskan sebagai ilmu penegetahuan empiris tentang eksistensi manusia yang menggunakan metode analisis fenomenologis. Heidegger menawarkan metode fenomenologi (fenomenologi eksistensialisme) sebagi pembuka struktur eksistensial dan pengalaman eksistensial manusia. Dengan metode ini, Heidegger berusaha membawa 'fenomena' tampil ke depan."13

Heidegger adalah seorang fenomenolog dan fenomenologi, memerankan peran yang sangat penting dalam sejarah Psikologi, terutama psikologi. Berada dan ketidakberadaan manusia itu juga bisa melalui fenomenologi keberadaan manusia.

Sylvia sadar berada pada suatu ruang yang itu bukan pilihanya dan ia tak bisa menghindari ruang atau keberadaanya saat ini untuk menuju keinginginannya. Pada akhirnya adalah bahwa Sylvia tidak sedang berada dimanapun dan mengalami dirinya sebagai objek.

"Manusia yang melibatkan diri dan menyadarai bukan saja pribadi yang diinginkannya sebagai pilihannya. Akan tetapi juga seorang pembuat hukum. Sekaligus memilih bagi seluruh kemanusiaan maupun bagi dirinya sendiri, mustahil akan bisa melepaskan tangung jawab yang dalam dan menyeluruh. ${ }^{14,}$

\footnotetext{
${ }^{12}$ Ibid. hlm. 11

${ }^{13}$ Lathief Supaat, Psikologi Fenomenologi Eksistensialisme (Kendal,

${ }^{14}$ Ibid. hlm. 50
} 2010), hlm. 85. 
Keputusan Sylvia untuk menemukan kemungkinan kebebasan itu yang tidak pernah disertai kemungkinan-kemungkinan, dan tanggung jawabnya yang besar tidak dapat dihindari. Sebagai seorang pekerja kerani yang masih memiliki tanggung jawab terhadap keluarganya.

"May dalam (1953) yang selalu berkomentar terhadap pengalaman eksistensial manusia modern menyebut masalah utama adalah kekosongan. Kekosongan menujuk pada suatu kondisi manusia (individu) yang tidak mengetahui lagi apa yang diinginkannya dan tidak lagi memiliki kekuasaan terhadap apa yang terjadi dan dialaminya."15.

Kehampaan yang dialami Sylvia ketika ia sejak kecil dan ketidakadilannya diperlakukan sebagai seorang anak ia merasa kesepian hingga ia dewasa. Kehampaan telah mengubah individu modern menjadi manusia yang yang mengarahkan diri pada orang lain dalam rangka mencari pegangan atau petunjuk bagi penentuan kehidupannya.

Kesadaran akan eksistensi pada Sylvia yang selalu mengungkapkan kepekaannya di dalam dirinya dalam bentuk perasaan dan emosi. Bahwa manusia merasa senang, kecewa dan marah. Sylvia selalu mengungkapkan emosinya, kebencianya, terhadap bosnya dan keluarganya. Dia selalu menjumpai dunia di luar sana dan di sini adalah nasib.

Secara bertanggung jawab sikap Sylvia seharusnya segera mengambil alih semua kemungkinan untuk menjalin hubungan. Dengan kata lain Sylvia harus menerima semua kemungkinan hidupnya, ia harus menyelaraskan dan merangkaikan kemungkinan-kemungkinan tersebut menjadi dirinya sendiri yang bebas dan autentik yang tidak lagi terperangkap dalam melintas sempit.

\footnotetext{
${ }^{15}$ E. Koeswara, Psikologi Eksistensial (Bandung, 1987), hlm. 29
}

\section{UPT Perpustakaan ISI Yogyakarta}


Kebebasan manusia terletak dalam kesiapannya menerima dan membiarkan segalanya yang ada.

Usianya tak lagi muda umurnya 60 tahun ia memiliki pola pikir dan perasaan yang berbeda. Pengalaman selama ini dan kehidupan yang ia harus terima dengan memandang bahwa hidupnya memang untuk bekerja. Keinginannya untuk menikah dengan Paul sudah hilang dan sekarang ia memandang bahwa Paul adalah sahabat sejatinya. Sylvia sebagai manusia eksistensi merasa siap menerima dan membiarkan yang ada. Itulah pencapaian yang luar biasa.

"Aktor harus mampu menyelidiki asal mula dirinya sendiri untuk dapat tulus jujur pada realita eksistensi dirinya yang baru, yakni tokoh yang ia mainkan. Imajinasi penciptaan hal-hal yang mungkin terjadi. Namun semua itu akan ada dan terjadi."16

\section{F. Metode Penciptaan}

Metode merupakan cara teratur yang digunakan untuk melaksanakan suatu pekerjaan agar tercapai sesuai dengan yang dikehendaki, atau cara kerja yang bersistem untuk memudahkan pelaksanaan suatu kegiatan guna mencapai tujuan yang ditentukan.

"Peter Brook selalu menggunakan dasar dari pekerjaan proses berteaternya dengan menggunakan "Prasangka Yang Tidak Berbentuk. "Pekerjaan latihan harus mampu menciptakan suatu suasana di mana aktor dapat merasa bebas untuk menyatakan atau mengeluarkan apa saja yang banyak mereka sumbangkan pada latihan-latihan tersebut" Peter Brook"17.

Kita harus setia kepada orang lain. Dengan kata lain, kita harus percaya apa yang dilakukan orang lain artinya aktor, sutradara, tim kreatif mampu

\footnotetext{
${ }^{16}$ Rikrik El Saptaria, Acting Handbook, (Bandung,2006), hlm. 89

${ }^{17}$ Peter Brook, op. cit. hlm. 2
} 
menyampaikan banyak kemungkinan - kemungkinan pengalaman dan bagaimana kemungkinan-kemungkinan seperti itu dapat berkembang. Lewat proses, itulah dasar (basis) yang sering disebut stereoscopic vision sebutan ini yang sering usung Peter Brook untuk berteater. Aktor dapat menumpahkan semua pengalamanya untuk menciptakan tokoh. Pada proses pengkaryaan ini akan dilakukan:

\section{a. Training}

Setting dan property akan digunakan selama latihan guna mendukung memori - memori imajinasi dalam pantomim. Metode latihan dasar yang harus dilakukan aktor adalah :

1. Memori Bentuk, melatih memori otot/aktor terhadap bentuk-bentuk benda. Aktor harus mencermati bentuk benda tersebut dengan perangkat motoriknya. Kemudian, memvisualisasikannya tanpa benda.

2. Memori Berat, melatih memori otot aktor terhadap massa benda. Motorik aktor harus mampu menangkap perbedaan tensi otot yang terjadi saat mengangkat benda dengan berat berbeda. Tempo dari gerakan juga harus diperhatikan agar mampu menciptakan ilusi berat yang sempurna.

3. Memori Jarak, letak benda tidak bisa berubah tanpa sebab. Sehingga motorik aktor harus dilatih agar mampu mengingat letak benda yang diimajinasikannya.

4. Memori Ruang, ruang harus tergambar melalui gestur aktor. Aktor harus mencoba berada di ruang yang berbeda-beda, mememorikan gesturnya, kemudian mempraktekkannya di ruang kosong.

\section{UPT Perpustakaan ISI Yogyakarta}


b. Rehearsal

\section{Freestyle}

Salah satu latihan yang dilakukan sebelum memasuki pelatihan-pelatihan, hal ini sangat diperlukan seorang aktor yang harus bebas mengekspresikan tubuh, suara, memori dan imajinasi.latihan ini bisa dilakukan dengan iringan musik maka tubuh akan bergerak sesuai dengan emosi yang ada pada musik tersebut. Banyak hal yang dirasakan ketika kita dapat melakukanya dengan konsentrasi yang baik. Gerak tubuh biasanya melampaui dengan kemampuan kita biasanya tanpa kita sadari.

Dengan melakukan reahelsel dan training dan seperti Prroses Peter brook dari semua kemungkinan - kemungkinan maka aktor, sutradara, bisa menyatukan perbedaan tersebut lalu kemudian sutradara membuang yang tidak perlu dengan sesuai kebutuhan naskah selama proses yang akan dilakukan.

\section{UPT Perpustakaan ISI Yogyakarta}

